\title{
9
}

\section{Conclusion: Implications for Policy and Practice}

\section{Introduction}

In Chap. 1, we explored the current discourse around adoption. Past adoption practices have been rightly criticised for a number of systemic and blatant injustices and also for a common lack of transparency. However, it is important to be transparent not only about children's origins but also about the reasons why some are permanently removed from birth families. Child maltreatment does occur and can have permanent, serious and sometimes fatal consequences. We argued that in spite of the injustices of the past and concerns about some current practices, if practised within a robust rights and ethics framework, adoption can be an appropriate intervention for the small group of abused and neglected children in out-of-home care who cannot safely return to their birth families (Palacios et al., 2019). For these children, the question professionals have to resolve is not whether or not they should return home, but whether it would be in their best interests to be adopted or remain in out-of-home care.

This book has traced the outcomes of a cohort of children who, following such a best interests decision, were adopted from care through 
Barnardos' Find-a-Family in New South Wales, Australia. Almost all of them had been significantly abused or neglected and none could safely return to their birth parents. We have examined the characteristics and experiences of these children, their adoptive parents and birth parents and attempted to identify factors which contributed to their resilience. A fundamental feature of the programme was the expectation of regular face-to-face contact with birth family members as part of the adoption plan, mandated and upheld by the courts; we explored the value of contact for the adoptees and their adoptive parents, and its impact on life trajectories. The findings have implications for adoption policy and practice throughout Australia; but they are also relevant in the many jurisdictions such as the USA, the UK and parts of Europe where the adoption of children from care, and particularly open adoption, are hotly debated issues.

\section{The Study}

All 210 adoptees were traced from notification of abuse or neglect to placement in permanent homes. Almost half of them (93: 44\%) were traced from entry to their adoptive homes until the follow-up cut-off date, an average of 18 years after permanent placement.

The study supports the findings from international research on adoptions of children from out-of-home care (e.g. Grotevant et al., 2007; Selwyn et al., 2006; Selwyn et al., 2014; Thomas, 2013). These show that the profile of this population is very different from that of infants relinquished for adoption by lone parents in the twentieth century (see Parker, 1999). Almost all of the adoptees in the Barnardos cohort had been seriously abused or neglected while living with their birth families; most had been exposed to a range of other adverse childhood experiences that are known to be associated with poor physical and mental health outcomes in adulthood, including premature mortality (Felitti et al., 1998). Birth parents were struggling with complex combinations of substance misuse, mental health problems and domestic abuse; there is no evidence that they had sufficient capacity to change and provide safe homes for their children within an appropriate timeframe. Apart from a very few 
children who were voluntarily relinquished, also in response to maltreatment concerns, all the children in the study were the subject of child protection orders. Those who were not placed for adoption were expected to remain in long-term foster care until they aged out at 18 .

Delays in professional decision-making, repeated experiences of separation and loss, and unstable placements in out-of-home care had compounded the vulnerability of the Barnardos adoptees: by the time they entered their adoptive homes, all had reached the threshold for significantly increased risk of poor adult outcomes on at least one of 11 criteria; almost half of them had reached it on six. The children's previous experiences were reflected in developmental delays, high levels of behavioural disturbance and emotional problems at entry to their adoptive homes.

Data from the core follow-up sample $(N=93)$ show that at entry to their homes, adoptive parents rated $13 \%$ of the adoptees as in poor physical health and $38 \%$ in poor or very poor mental health. Three-quarters of them had problems at school, and at least three-quarters faced specific challenges which required specialist support. Almost half the adoptive parents found the first year of the placement stressful. However, most adoptees saw improvements in their physical and mental health after being permanently placed, and about two-thirds saw improvements in their academic performance.

Data from this core follow-up sample show that most adoptees established permanent relationships with adoptive parents who came to regard them as their own children and supported them into adulthood. Most adoptees stayed in their adoptive homes until they were at least 21 and then left for normative reasons. Twelve left their adoptive homes before they were 18 , indicating a disruption rate of $13 \%$. About a quarter of the adoptions showed an underlying fragility in that the adoptee had run away or temporarily left home on at least one occasion. However, the distinguishing feature was that adoptees could return and that most adoptive parents continued to support them after they had left. There were no dissolutions and no evidence that any child returned to out-ofhome care. The adoptees were less likely to maintain close relationships with their adoptive parents than the normative Australian population, but the relationship was twice as likely to persist as that between care leavers and former foster carers. 
Data concerning the 60 young people who were 18 or over at the time of follow-up show that, in comparison with the normative Australian population, adult adoptees had similar, though slightly less positive, outcomes in terms of basic and higher education, and a similar proportion were in full-time education, employment or training. However, they showed markedly more negative outcomes in terms of being NEET (not in education employment or education), substance misuse and being the victim of domestic abuse (men).

In comparison with a sample of care leavers (Cashmore \& Paxman, 2007), the adoptees showed significantly more positive outcomes in terms of basic and higher educational qualifications and employment. However, they showed significantly worse outcomes in terms of substance use and some indication of greater levels of substance misuse and mental health problems. A higher proportion of adult adoptees showed evidence of successful adult functioning than care leavers, but the difference was not statistically significant.

Adoptees who met the criteria for success on our composite measure of adult functioning (Cashmore \& Paxman, 2007) tended to have had less exposure to recognised risk factors than those who did not succeed, but the differences were not statistically significant. The only factors that were found to have a significant relationship with adult functioning were exposure to polyvictimisation (all four types of abuse) before separation from birth families (associated with less successful functioning) and experiences of sensitive parenting in adoptive homes (associated with those who met the criteria for success). Our overall classification of vulnerability (Chap. 3) was not a reliable predictor of adult outcome, except for those adoptees at the extreme ends of the spectrum. Adoption by parents who could meet children's therapeutic needs appeared to act as a powerful protective factor in promoting resilience and facilitating developmental recovery, but it was not sufficient to counteract the most damaging early experiences (see also Rutter et al., 2007; Sonuga-Barke et al., 2017).

Most adoptees (87\%) had face-to-face post-adoption contact with at least one birth parent. They also had face-to-face contact with grandparents and siblings. More than half were seeing at least one birth relative at the time of the follow-up. Adoptive parents accompanied their children to contact meetings. Contact was difficult for $60 \%$ of the sample, the 
most significant issue being birth parents' continuing problems. Although it was painful, most (69\%) adoptees and adoptive parents thought that contact had been beneficial. There is no evidence that open adoption jeopardised the stability of adoptive homes; it was the placements where adoptive parents were less open to face-to-face contact and had less empathy with birth parents that were the most fragile (see also Grotevant et al., 2007; Neil, 2003).

Evidence concerning the impact of contact on adoptees' outcomes was mixed. There was little statistical association between face-to-face contact and adoptees' mental health or adult outcomes, except one finding that, for some adoptees, contact with birth fathers had a detrimental impact. However, there are indications that contact helped adoptees develop a strong sense of identity, come to terms with their parents' limitations, accept the reasons why adoption had been necessary and move on. Those who did so appeared to have better outcomes.

The ability of adoptive parents to accept adoptees as their own children was perhaps the most significant factor in facilitating successful outcomes. The presence of committed substitute parents, who regarded them as their own children and supported them through the transition from adolescence to adulthood regardless of enduring and challenging emotional and behavioural difficulties, was the feature that distinguished the experiences of adoptees from those of most care leavers; it is likely to have had a major impact on adult outcomes. The change of legal status conferred by adoption underpinned the development of a committed relationship between most adoptive parents and adoptees and helped mitigate the consequences of their past adversities. Ongoing contact with birth parents facilitated the development of this relationship.

\section{Implications for Child Protection Policy and Practice}

Evidence from this study supports the wide body of research that has found that abuse and neglect in early childhood have long-term consequences that are difficult to escape (see Brown \& Ward, 2013, for 
summary). We know that, like other children adopted from care, the Barnardos adoptees had experienced high levels of abuse and neglect before being separated, that there was a continuing risk of maltreatment within their birth families and that they could not safely return home (see also Selwyn et al., 2006). It was also Barnardos' policy to focus on children who were 'hard to place', indicating that even within this very vulnerable population, the Barnardos adoptees had been exposed to exceptionally poor early childhood experiences. Abuse and neglect in early childhood, in many cases compounded by adverse experiences in out-of-home care, are likely to lie behind the high levels of emotional and behavioural difficulties evident at entry to their adoptive homes and the ongoing mental health issues present amongst adult adoptees. Although the adult adoptees did well in terms of education and employment, many were nevertheless reliant on continued support from adoptive parents and partners to help them function in an adult world; even those who were living very successful adult lives showed an underlying vulnerability.

Evidence of the continued impact of abuse and neglect indicates a need for a focus on policies aimed at addressing parents' difficulties when they start to emerge and then effectively preventing maltreatment from occurring. Addressing abuse and neglect as a public health issue, with a whole population focus on improving parenting, has been found to be effective in some countries (Davies \& Ward, 2012). Where abuse and neglect have occurred, there is also a need for long-term support for those affected, whether they are adopted, placed in long-term foster homes, or remain living with birth parents (see Brown et al., 2016).

\section{Children Who Cannot Remain with Birth Parents}

\section{Delays in Professional Decision-Making}

The study has important implications for professional decision-making where children cannot safely remain at home. Polyvictimisation was 
significantly associated with poor outcomes in adulthood. Long-term exposure to abuse pending a decision to separate them from birth families, repeated failed attempts at restoration and instability in care pending a permanent placement are also likely contributors to the adoptees' vulnerability (Brown et al., 2016). There is no evidence that birth parents had been able to overcome their difficulties by the time the children were adopted; more timely decision-making and more robust assessments of parental capacity to change might have reduced the adoptees' exposure to abuse and neglect and their consequences (Ward et al., 2014, 2019).

\section{Quality of Out-of-Home Care}

The study raises questions about the quality of out-of-home care, although it should be noted that, because it spans a 30-year timeframe, some of the deficits underlying the adoptees' experiences may have since been addressed. Nevertheless, it is noteworthy that 100 (48\%) adoptees had had three or more placements before entering their adoptive homes, and 10 had moved more than ten times. Placement moves happened both before and after entry to Barnardos. The impact of these experiences is evident from the interviews, where adoptive parents described children who hid from visitors for fear they had come to move them again and where remarks from adoptees such as the following were commonplace:

But I feel like I - you know, moving around to different homes so often and changing primary schools was just really - there was no stability in that, and that's what a child needs: they need stability growing up. (Young woman, aged 10 when permanently placed, aged 21 when interviewed)

Placement instability is a recognised and continuing problem in the Australian child welfare system (Wulczyn \& Chen, 2017). It is also an issue in the USA (Blakey et al., 2012), Sweden (Vinnerljung et al., 2014), England (Ward, 2009) and many other countries. In England, about $30 \%$ of moves in out-of-home care occur because of a breakdown in the relationship between carer and child. However, over half (54\%) are administrative moves, engendered as part of the case management 
process (Ward, 2009); Delfabbro et al. (2005) found around 60-70\% of placement moves occurred for the same reason in Southern Australia. Action should be taken to monitor moves within out-of-home care and their reasons and to reduce them wherever possible.

There is also evidence of poor quality day-to-day care in foster homes. Interviews provided some evidence of sexual and emotional abuse in foster care, but this appears to have been disclosed and addressed at the time. However, adoptive parents also described children being placed in their homes after many months (or years) in out-of-home care who were developmentally delayed because of lack of stimulation, or who had no experience of rules or boundaries. The following quotation is from a young woman who had spent seven years in foster care before entering her adoptive home:

I think I probably many times would've thought, "Oh, she's the worst. She's giving me all these rules and not letting me do these things". But now when I look back on it, that was just a healthy adult providing boundaries for a child, which I never had in my life. (Young woman, aged 10 when permanently placed, aged 21 when interviewed)

\section{Implications for Permanency Planning}

We do not know how many foster homes were abusive or of sub-optimal quality. Some of the adoptees had experienced highly supportive, stable long-term foster placements, many of them with carers who went on to adopt them. Nevertheless, the findings do throw into sharp relief the differences between long-term foster care and adoption. Adoption provided the children with greater stability than most had previously experienced in foster care. At the time they were followed up, those who were still living with their adoptive parents had been there for an average of 13 years, and this includes adoptees who had had numerous previous foster or residential placements. We do not know how many adoptees would have gone on to achieve stability had they remained in foster care. The breakdown rate $(13 \%)$ is lower than that of the placements of children in the Pathways of Care Longitudinal Study (POCLS) of out-of-home care in 
New South Wales, which gives a 'conservative' estimate of $17 \%$ 'following the Wave 1 interview' (Wulczyn \& Chen, 2017). It is also substantially lower than the $28-30 \%$ found for placements in long-term foster care in the UK (Biehal et al., 2010), or the $24 \%$ found for similar placements in Sweden (Vinnerljung et al., 2014). However, it is slightly higher than that found in a study of children in long-term foster care in Norway, in which $12.5 \%$ of placements with kinship and non-kinship carers who 'believed that the child should grow up in their family' disrupted after an average of 8.9 years (Holtan et al., 2013). The authors of this study point out that in Norway, as in other Nordic countries, long-term stable foster care is the preferred route to permanence, and adoption is seldom an option; their findings suggest that, given the appropriate support, longterm foster carers can provide similar levels of stability if the expectation is that they will provide a 'family for life'.

Comparison with Cashmore and Paxman's (2007) study of wards leaving care, who were of similar age to many of the Barnardos adoptees, showed that adoptees tended to do better in terms of education and employment than care leavers. In part this may be due to the determination with which adoptive parents sought out specialist help to enable their children to overcome past deficits in education as well as their psycho-social difficulties. However, the findings also showed that most adoptive parents provided much greater support for young people making the transition from adolescence to adulthood than foster carers were able to offer. Adoptees were approximately three years older than care leavers when they left home, they could and did return when plans went awry, and they continued to receive practical and emotional support from adoptive parents after they had achieved independence. This type of enduring parental support was rarely available to care leavers; it is likely to be a key reason why, despite stronger evidence of enduring mental health issues, adoptees were more likely to achieve satisfactory functioning in adulthood.

Finally, the change in legal status that adoption brought seems to have given the children the sense of belonging and security they needed to achieve a positive sense of identity. It provided the foundation for the formation of a new family, to which both adoptive parents and adoptees developed a life-long commitment. Triseliotis' (2002) review of research 
literature on outcomes of long-term foster care and adoption concluded that 'even when long-term fostering lasts, the children still feel less secure and have a weaker sense of belonging than those who are adopted' (p. 28). He identified the legal status the adoption order gave them as a key element in adoptees' greater sense of belonging.

As well as showing the benefits of adoption, the findings also indicate that, where this is not a suitable option, much could be done to improve outcomes for care leavers. Although legislation and policy designed to support care leavers as they make the transition to independence in adulthood have been introduced in some countries including Australia (Mendes, 2020; Stein \& Munro, 2008), this has generally been poorly implemented (Strahl et al., 2020). Stronger, and more effective policies designed to bring the experiences of young people ageing out of care to a closer approximation of normative family life, allowing them to stay in foster homes until they are older, to return when plans fall through and to access continuing support as independent adults would reduce the vulnerability of this group and be likely to improve their long-term outcomes.

\section{Implications for Adoption Policy and Practice}

The findings indicate that adoption can provide greater stability, a stronger sense of belonging and better support for young people making the transition towards adulthood than long-term foster care usually provides. There is therefore a strong argument for making it more widely available to children in out-of-home care who cannot safely return home within a timeframe that is consonant with their developmental needs. However, the findings also have considerable implications for the recruitment and training of adoptive parents; for the support of adoptive and birth families over contact; and for post-adoption support to adoptive parents and children. 


\section{Recruitment of Adoptive Parents}

Open adoption of children from out-of-home care is not the same as the closed adoptions of infants relinquished by single mothers that took place in the twentieth century, and adoptive parents now face very different challenges. Better understanding of the needs of adopted children and the detrimental impact of past policies has led to the development of much greater transparency in adoption practice: if open adoption plans are followed, the secrets and lies that characterised adoption in the past can no longer persist. The vast majority (87\%) of the adoptees had postadoption face-to-face contact with at least one birth parent, and almost all $(93 \%)$ had contact with at least one birth family member. In the Finda-Family programme, adoptive parents made the arrangements for contact and accompanied their adoptees to contact meetings. This meant that some level of communication between the parties involved was unavoidable and, as a result, some of the fantasies were dispelled: when they had to meet on a regular basis, it was harder for adoptive parents to cling to the myth that birth parents who had maltreated their children were monsters or for birth parents to believe that adoptive parents had stolen their children. Adoptees were also less likely to fantasise about returning to an idealised birth family when they saw them regularly and their problems were, sometimes painfully, exposed.

Some of the most successful adoptions appeared to be those in which the adoptive family included the children's relatives as honorary members of their own extended family. Although this was not always possible, or even desirable in some cases, it is noteworthy that the few adoptions in which contact was discouraged were markedly less successful in that, in interviews, these adoptees focused extensively on their past experiences and did not appear to have been able to move on. Concerns are sometimes raised that contact will undermine placements and increase the likelihood of adoptees returning to birth parents (Dodgson, 2014; Turkington \& Taylor, 2009): this study found that the opposite was the case-it was those adoptees who did not have contact who were more likely to seek out birth family members and return to them (see also Grotevant et al., 2007). 
Recruitment policies should reflect the reality of open adoption. Prospective adoptive parents need to be able to relate to birth family members without hostility and to understand their situation. There is no evidence from this study that adoptive parents whose primary motivation was their own infertility were less able to do this than adoptive parents who were motivated by a desire to help a child.

Recruitment agencies also need to be aware that one of the consequences of open adoption from out-of-home care is that it brings the role of adoptive parents closer to that of foster carers and this should be a consideration in setting eligibility criteria. Prospective adopters may need to be able not only to empathise with birth parents but also to provide therapeutic parenting to children who have experienced early trauma (Staines et al., 2019). The Barnardos adoptive parents had all been dual registered as foster carers, and many of them fostered their adoptees for several years before adopting them. This may have been one of the factors that led to the success of the programme.

\section{Contact}

The study shows that it is possible to recruit adoptive parents who will support open adoption practice. It also shows that regular face-to-face contact with birth family members can be maintained: at follow-up, on average 18 years after placement, $56 \%$ of the adoptees were still seeing at least one member of their birth family. Just over two-thirds (69\%) of both adoptive parents and adoptees thought that, in the long run, contact had been beneficial. However, $60 \%$ of adoptive parents had found contact problematic, and more than one in four (28\%) adult adoptees thought they had never benefitted from it. It should also be noted that adoptees who had no post-adoption contact with birth fathers were significantly less likely to have mental health problems in adulthood.

Data from the interviews raise a number of issues concerning contact that underlie these mixed findings and indicate where practice improvements might be made. ${ }^{1}$ Almost all respondents (88\%) thought that

\footnotetext{
${ }^{1}$ Interviewees tended not to distinguish between contact pre and post the adoption order; these findings therefore apply to all contact after the child had been permanently placed.
} 
Barnardos should continue their policy of asking adoptive parents to accompany children to contact sessions, mainly to ensure that the child was safe and was not being manipulated by birth parents trying to undermine the placement. This is an important feature of the Barnardos programme both for adoptees and for children in foster care; and there is much to be learnt from it. Although adding to the burden placed on adoptive parents, it was much appreciated by the adoptees and is likely to be more beneficial than the common practice of arranging for children in care to be taken to meet parents in contact centres by volunteers who do not know them, their foster carers or their birth parents (see Humphreys $\&$ Kiraly, 2011).

It was also evident that practitioners should be clear about the purpose of contact, particularly where children are obviously frightened by birth parents; where they make it clear that they do not want to spend time with adults who have hurt them in the past; where relatives are abusive towards the adoptee; and where they arrive at contact sessions under the influence of alcohol or drugs. These are the types of situations in which there is a risk that face-to-face contact will re-traumatise the child and where careful consideration might be given to questioning its value at that particular time. It is evident from the interviews that 'agency' or the opportunity to make their own decisions about contact was valued by the adoptees. They had their own views about how contact should be tailored to the needs of each individual child (see also Neil et al., 2015).

Ask the children how much they want to see birth family. (Response to openended survey question from young man aged 18 months when permanently placed, aged 11 at follow-up)

Sometimes you need to look at the child to pick up on what they are feeling to try to limit the birth family contact. (Young woman, aged 7 when permanently placed, aged 35 when interviewed)

They should not be enforced. I found them traumatic as a child. (Young woman, aged 7 when permanently placed, aged 38 when interviewed) 
I would have preferred to just see my dad and nan. (Young woman, aged 10 when permanently placed, aged 32 when interviewed)

In certain situations, face-to-face contact may not always be the most beneficial option. One adoptee thought that indirect contact would be more appropriate for children who had been seriously abused as he had been:

If they don't want to see them, and it affected them like it did me, kind of like figure something out to avoid that, that tension and stuff... I mean, for littler kids, you could always do just scrapbooking and stuff like that. And make it creative. But then, at the same time, it's informing them about their life. And then with older ones, it's kind of similar process, like a similar approach,... and just like kind of show them something that shows them their past, and stufflike that. (Young man, aged 2 when permanently placed, aged 18 when interviewed)

\section{Training}

The evidence discussed above indicates that training for prospective adoptive parents as well as for child welfare professionals should include the factors that increase (or reduce) the likelihood that parents will abuse their children, the impact of abuse and neglect on children's subsequent development, the impact of secrecy and deception on children's sense of identity, and the rationale behind open adoption policy and practice.

Training also needs to cover therapeutic parenting skills within the context of the needs of children adopted from care. As we have seen, a high proportion of the adoptees had significant emotional and behavioural problems when first placed with their adoptive families; they also displayed a range of developmental delays including poor cognitive development. Adoptive parents needed to learn both how to better support their children themselves and also how to access self-help groups and specialist services where appropriate. In the words of one adoptive parent: 
'These are damaged children and I realise now that placing them in a loving home is not enough, I feel that I may have been better equipped if I had attended some sort of counselling or self-help adoptive parents' group?

I believe that adoptive parents would benefit from training sessions in how to better managelcounsel a child who had been repeatedly let down by their birth family who did not show up for an arranged meeting, this I believe was a big factor in the low self-esteem of my daughter.' (Adoptive parent of young woman, aged 6 months when permanently placed)

\section{Post-adoption Support}

Finally, some of the key findings from the study add to the already extensive evidence base that demonstrates the enduring impact of abuse and neglect in early childhood (Brown et al., 2016; Felitti et al., 1998; Gerin et al., 2019; McCrory et al., 2017). They also provide further evidence of the persistent effects of early trauma even after those affected have spent many subsequent years in stable, loving homes (see, for instance, Selwyn et al., 2014; Sonuga-Barke et al., 2017). Adoption is intended to create a new family, and until relatively recently it was assumed that, after the order had been made, there would no longer be a need for specialist support; however there is now substantial evidence to show that adoptive families may need help at any stage in the child's development, and particularly in the teenage years (Adoption UK, 2020; Livingston Smith and Donaldson Adoption Institute, 2004; Selwyn, 2017). A recent survey of adoptive families in the UK found that $48 \%$ of those with older children were experiencing severe challenges and $42 \%$ of 16-25-year-old adoptees had been engaged with mental health services in the previous year (Adoption UK, 2020).

Barnardos assumed that the provision of specialist post-adoption support services would interfere with the process of normalising the new family, and adoptive parents who ran into difficulties were signposted to universal services within the community. However, it is clear from the interviews, and also from survey responses, that many adoptees and their families continued to require specialist support, particularly during adolescence, but also often into adulthood. The findings from the study add 
to the body of evidence indicating a need for post-adoption support services that can be accessed as and when required.

In my case, all helped ceased when the adoption went through. I had problems but had no one to turn to.... I think help is needed after adoption. I probably thought adoption would solve most of my child's problems, but it didn't. But I suppose that it is not Barnardo's responsibility for ongoing aftercare... although I do have a friend in my last caseworker. It is just hard as everything stops. Financially... keeping a teenager with ongoing medical and psychologic problems in a school with no financial support is very hard... (Adoptive parent of young woman, aged 9 when permanently placed)

\section{Conclusion}

A number of concerns underlie the reluctance to develop stronger policies to support adoption from care in Australia. These include concerns that children placed for adoption may have been inappropriately taken into care; that adoption disregards genetic and birth bonds; that legal ties with wider family members may be severed; and that adoptees are likely to suffer enduring identity problems. There are also concerns that adoptees may be subject to abuse in adoptive homes; that decisions to pursue adoption may not be focused on children's best interests; and that adoption may simply be a means of transferring and privatising the costs of out-of-home care, particularly when post-adoption support services are inaccessible or insufficient (Australian Federal Parliament House of Representatives Standing Committee on Social Policy and Legal Affairs, 2018; Cashmore, 2000). Similar concerns are also found in countries such as the UK and the USA, where adoption is well established as an integral part of the child protection system (DelBalzo, 2007; Ward and Smeeton, 2017), and in other countries where it is less common (Schrover, 2020). Such concerns must be acknowledged.

While inadequate assessment and poor decision-making undoubtedly lead to injustices in some individual cases, many of the findings from the study address these concerns. Almost all the adoptees had experienced significant levels of abuse or neglect before removals from birth families or were at high risk of maltreatment because of their siblings' experiences. 
All adoptees had gone through rigorous legal processes in both the Children's Court and the Supreme Court. The birth parents of 24 children contested the adoptions in court, but there was no evidence that these parents had the capacity to meet their needs, and no evidence of inappropriate removal. Nor was there evidence that Aboriginal children were being targeted or affected by adoption policy. The Find-a-Family programme does not routinely take referrals for Aboriginal children, and only five $(2 \%)$ of the full cohort were found to be of Aboriginal heritage post placement.

Legal decisions appear to have been made in accordance with the best interests of the child; evidence from the adoptees also makes it clear that almost all believed that adoption had been right for them. They valued the change in legal status because it brought security and made them full members of a new family. However, for most children, adoption did not sever links with family members - the open adoption policy was followed in almost all cases: $93 \%$ of the children had post-adoption contact with at least one birth family member and 56\% were still seeing them when they were followed up, on average 18 years later. There is evidence that the open adoption policy also helped adoptees come to terms with their past and develop a stronger sense of identity.

Abuse can occur in any type of family and it is true that children who are vulnerable for other reasons are at greater risk. Abuse is also relatively common in out-of-home care (Royal Commission into Institutional Responses to Child Sexual Abuse, 2017). The study uncovered one instance of sexual abuse in an adoptive home which had been disclosed and led to the removal of the perpetrator, and one instance of emotional abuse that had not apparently been previously disclosed. As far as we know, about $2 \%(2 / 93)$ of the sample had been abused in their adoptive homes compared with $8 \%$ of the full cohort $(16 / 210)$ who had made formal allegations of abuse while in foster or residential care.

While it is true that infertility was the primary motivation for the majority of the adoptive parents, there is no evidence to support the view that decisions to place for adoption were driven by adult interests. As we have seen, before the placement was made, there had been evidence of abuse likely to cause significant harm and a decision that the adoptees could not safely return home. 
Although the study addresses many of the concerns that have been raised about adoption, it also raises some questions. The findings shed light on a number of areas where policy and practice might be strengthened, both in the field of adoption and in the wider range of child protection services. However, one criticism of policies designed to support adoption is that, in common with other child protection interventions, it is a 'sticking plaster' service, designed to mitigate the consequences of maltreatment rather than to address its causes. The high proportion of infants removed from birth parents within the first year of life in Australia, England, the USA and the Scandinavian countries has become a major concern (Backhaus et al., 2019; Broadhurst et al., 2018). One factor is likely to be an increase in poverty and reduction of family support services following the financial crash of 2008 (Thomas, 2018). Poor socioeconomic circumstances and inadequate family support services are among the stressors which underlie some of the parental factors such as mental health problems, substance misuse and domestic abuse which compromise parenting capacity, place infants at risk of significant harm and lead to their removal (Backhaus et al., 2019). Policies to support adoption from care have been criticised on the grounds that they can be a means of avoiding the need to address the systematic reasons why abuse and neglect occur and to support birth parents to provide safe and nurturing homes within an appropriate timeframe (Australian Federal Parliament House of Representatives Standing Committee on Social Policy and Legal Affairs, 2018).

However, while there is an obvious need to provide better support for parents and introduce stronger policies to prevent the occurrence of maltreatment, children still need to be protected from harm. There is now a wide body of evidence showing the extent to which abuse and neglect compromise children's long-term life chances (summarised in Brown \& Ward, 2013); as long as child maltreatment remains prevalent, there will be a need for child protection interventions. This study adds to the body of evidence that shows that, where children cannot safely remain with or return to their birth families, adoption offers opportunities for recoveryto-normal development. Policies that aim to place these children for adoption are based on evidence that indicates this will offer them a better chance of stability, stronger long-term commitment, a higher level of 
support through the transition to adulthood and a greater chance of becoming part of a family for life than foster care is currently able to offer either in Australia or in many other countries. The evidence presented in this book suggests that for most of the Barnardos adoptees, this proved to be the case.

\section{Key Points}

- Summary findings from the research study indicate the extreme vulnerability of the adoptees at entry to their adoptive homes and the developmental recovery most achieved after placement. Adoptees were more vulnerable than care leavers, but more achieved successful functioning in adulthood. In comparison with long-term foster care, adoption appears to have provided children with greater stability, a stronger sense of security and belonging and more support as they made the transition to adulthood. The commitment of adoptive parents acted as a powerful protective factor, enhancing resilience and mitigating some of the consequences of early adversity.

- Most of the adoptees had experienced significant abuse and neglect before separation from birth parents. Greater focus in child protection policy on carefully targeted family support that addressed parents' difficulties might have prevented abuse from occurring and enabled some adoptees to remain with birth families.

- Early experiences of trauma had an enduring impact on the adoptees' wellbeing. There is a need for long-term support for children who are struggling with the sequelae of abuse, wherever they are living. For adoptive families this needs to be reflected in robust post-adoption support services, available for families to call upon at their discretion.

- The findings indicate a need for more robust assessments of parental capacity to change and more timely decision-making where children cannot remain safely with birth parents.

- Open adoption of children from care has brought the role of adoptive parents closer to that of foster carers. This needs to be reflected in recruitment and training policy and practice.

- Although most adoptees and adoptive parents thought that postadoption contact had been beneficial in the long run, it had often been 
problematic, and 28\% of adoptees thought they had not benefitted. Contact needs to be carefully managed and tailored to the needs of each child.

- Policies that required adoptive parents to organise and be present during contact sessions were valued, as were opportunities for older adoptees to make their own decisions about contact arrangements.

- Policies designed to strengthen families and reduce the prevalence of abuse are clearly necessary; however, the study adds to the body of evidence that shows the benefits of adoption from care for children who have suffered or are likely to suffer significant harm and who cannot safely live with birth families.

\section{References}

Adoption UK. (2020). Adoption barometer: A stocktake of adoption in the UK. Adoption UK. https://www.adoptionuk.org/Handlers/Download.ashx? IDMF=c79a0e7d-1899-4b0f-ab96-783b4f678c9a. Accessed 2 Oct 2020

Australian Federal Parliament House of Representatives Standing Committee on Social Policy and Legal Affairs. (2018). Breaking barriers: A national adoption framework for Australian children - Inquiry into local adoption. Australian Government.

Backhaus, S., Ott, E., \& Ward, H. (2019). International network on infants, toddlers and child protection: Report of inaugural meeting. Oxford University.

Biehal, N., Ellison, S., Baker, C., \& Sinclair, I. (2010). Belonging and permanence: Outcomes in long-term foster care and adoption. BAAF.

Blakey, J. M., Leathers, S. J., Lawler, M., Washington, T., Natschke, C., Strand, T., \& Walton, Q. (2012). A review of how states are addressing placement stability. Children and Youth Services Review, 34(2), 369-378.

Broadhurst, K., Alrouh, B., Mason, C., Ward, H., Holmes, L., Ryan, M., \& Bowyer, S. (2018). Born into care: Newborn babies subject to care proceedings in England. The Nuffield Family Justice Observatory: Nuffield Foundation.

Brown, R., \& Ward, H. (2013). Decision-making within a child's timeframe, Report to Department for Education. Childhood Wellbeing Research Centre. 
Brown, R., Ward, H., Blackmore, J., Thomas, C., \& Hyde-Dryden, G. (2016). Eight-year-olds identified in infancy as at risk of harm: Report of a prospective longitudinal study. RR543. Department for Education. https://assets.publishing.service.gov.uk/government/uploads/system/uploads/attachment_data/ file/534376/Eight-year-olds_identified_in_infancy_as_at_risk_of_harm.pdf. Accessed 20 Oct 2020

Cashmore, J. (2000). What the research tells us: Permanency planning, adoption and foster care. Children Australia, 25(4), 17-23.

Cashmore, J., \& Paxman, M. (2007). Wards leaving care: Four to five years on. University of New South Wales.

Davies, C., \& Ward, H. (2012). Safeguarding children across services. Jessica Kingsley Publishers.

DelBalzo, J. (2007). Unlearning adoption: A guide to family preservation and protection. Book Surge Publishing USA: booksurge.com.

Delfabbro, P., King, D., \& Barber, J. (2005). Children in foster care - Five years on. Children Australia, 35(1), 22-30.

Dodgson, L. (2014, November 11). Post-adoption contact: all change or more of the same? Family Law Week. https://www.familylawweek.co.uk/site. aspx?i=ed136606. Accessed 18 Dec 2020.

Felitti, V. J., Anda, R. F., Nordenberg, D., Williamson, D. F., Spitz, A. M., Edwards, V., Koss, M. P., \& Marks, J. S. (1998). Relationship of childhood abuse and household dysfunction to many of the leading causes of death in adults. The adverse childhood experiences (ACE) study. American Journal of Preventive Medicine, 14(4), 245-258.

Gerin, M. I., Hanson, E., Viding, E., \& McCrory, E. J. (2019). A review of childhood maltreatment, latent vulnerability and the brain: Implications for clinical practice and prevention. Adoption and Fostering, 43(3), 310-328.

Grotevant, H. D., Wrobel, G. M., Von Korff, L., Skinner, B., Newell, J., Friese, S., \& McRoy, R. G. (2007). Many faces of openness in adoption: Perspectives of adopted adolescents and their parents. Adoption Quarterly, 10(3-4), 79-101.

Holtan, A., Handegard, B., Thornblad, R., \& Vis, S. (2013). Placement disruption in long-term kinship and non-kinship foster care (2013). Children and Youth Services Review, 35, 1087-1094.

Humphreys, C., \& Kiraly, M. (2011). High-frequency family contact: A road to nowhere for infants. Child \& Family Social Work, 16, 1-11. 
Livingston Smith and Donaldson Adoption Institute. (2004). Facilitating adoptions from care. BAAF.

McCrory, E. J., Gerin, M. I., \& Viding, E. (2017). Annual research review: Childhood maltreatment, latent vulnerability and the shift to preventative psychiatry - the contribution of functional brain imaging. Journal of Child Psychology and Psychiatry, 58(4), 338-357.

Mendes, P. (2020). Happier 21st? Victoria's out-of-home care comes of age. Lens Monash University. https://lens.monash.edu/2020/12/03/1381837/ victorias-out-of-home-care-comes-of-age. Accessed 17 Dec 2020.

Neil, E. (2003). Understanding other people's perspectives: Tasks for adopters in open adoption. Adoption Quarterly, 6(3), 3-30.

Neil, E., Beek, M., \& Ward, E. (2015). Contact after adoption: A longitudinal study of post adoption contact arrangements. Coram BAAF.

Palacios, J., Brodzinsky, D., Grotevant, H., Johnson, D., Juffer, F., MartinezMorah, L., Muhamedrahimove, R., Selwyn, J., Simmonds, J., \& TarrenSweeney, M. (2019). Adoption in the service of child protection: An international interdisciplinary perspective. Psychology, Public Policy, and Law, 25(2), 57-72.

Parker, R. (1999). Adoption now: Messages from research. Wiley.

Royal Commission into Institutional Responses to Child Sexual Abuse. (2017).

Final report. Commonwealth of Australia. https://www.childabuseroyalcommission.gov.au/sites/default/files/final_report_-_preface_and_executive_ summary.pdf. Accessed 14 Jan 2021.

Rutter, M., Beckett, C., Castle, J., Colvert, E., Kreppner, J., Mehta, M., Stevens, S., \& Sonuga-Barke, E. (2007). Effects of profound early institutional deprivation: An overview of findings from a UK longitudinal study of Romanian adoptees. European Journal of Developmental Psychology, 4(3), 332-350.

Schrover, M. (2020, April). Parenting, citizenship and belonging in Dutch adoption debates 1900-1995. Identities. https://doi.org/10.1080/ 1070289X.2020.1757252.

Selwyn, J. (2017). The adoption of looked after maltreated children in England: Challenges, opportunities and outcomes. Developing Practice: The Child, Youth and Family Work Journal, 47(2017), 50-63.

Selwyn, J., Sturgess, W., Quinton, D., \& Baxter, C. (2006). Costs and outcomes of non-infant adoption. BAAF.

Selwyn, J., Wijedasa, D., \& Meakings, S. (2014). Beyond the adoption order: Challenges, interventions and adoption disruptions, RR 336. Department for Education. 
Sonuga-Barke, E., Kennedy, M., Kumsta, R., Knights, N., Golm, D., Rutter, M., Maughan, B., Schlotz, W., \& Kreppner, J. (2017). Child-to-adult neurodevelopmental and mental health trajectories after early life deprivation: The young adult follow-up of the longitudinal English and Romanian adoptees study. Lancet, 389, 1539-1548.

Staines, J., Golding, K., \& Selwyn, J. (2019). Nurturing attachments parenting program: The relationship between adopters' parental reflective functioning and perception of their children's difficulties. Developmental Child Welfare, 1(2), 143-158.

Stein, M., \& Munro, E. (2008). Young people's transitions from care to adulthood: International research and practice. Jessica Kingsley.

Strahl, B., van Breda, A., Mann-Feder, V., \& Schroer, W. (2020). A multinational comparison of care-leaving policy and legislation. Journal of International and Comparative Social Policy, 2020, 1-16.

Thomas, C. (2013). Adoption for looked after children: Messages from research. BAAF.

Thomas, C. (2018). The care crisis review: Factors contributing to national increases in numbers of looked after children and applications for care orders. Family Rights Group.

Triseliotis, J. (2002). Long-term foster care or adoption? The evidence examined. Child \& Family Social Work, 7, 23-33.

Turkington, S., \& Taylor, B. J. (2009). Post-adoption face-to-face contact with birth parents: Prospective adopters' views. Child Care in Practice, 15(1), 21-38.

Vinnerljung, B., Sallnäs, M., \& Berlin, M. (2014). Placement breakdowns in long-term foster care - A regional Swedish study. Child \& Family Social Work, 22(1), 15-25.

Ward, H. (2009). Patterns of instability: Moves within the English care system: Their reasons, contexts and consequences. Children and Youth Services Review, 31, 1113-1118.

Ward, H., Brown, R., Blackmore, J., Hyde-Dryden, G., \& Thomas, C. (2019). Identifying parents who show capacity to make and sustain positive changes when infants are at risk of significant harm. Developing Practice, 54, 47-61.

Ward, H., Brown, R., \& Hyde-Dryden, G. (2014). Assessing parental capacity to change when children are on the edge of care: an overview of current research evidence. RR369. Centre for Child and Family Research, Loughborough 
University and Department for Education. https://assets.publishing. service.gov.uk/government/uploads/system/uploads/attachment_data/ file/330332/RR369_Assessing_parental_capacity_to_change_Final.pdf. Accessed 30 Dec 2020.

Ward, J., \& Smeeton, J. (2017). The end of non-consensual adoption: Promoting the wellbeing of children in care. Practice, 29(1), 55-73.

Wulczyn, F., \& Chen, L. (2017). Placement changes among children and young people in out-of-home care. Pathways of Care longitudinal study: Outcomes of children and young people in out-of-home care. Research Report 8. NSW Department of Family and Community Services.

Open Access This chapter is licensed under the terms of the Creative Commons Attribution 4.0 International License (http://creativecommons.org/licenses/ by/4.0/), which permits use, sharing, adaptation, distribution and reproduction in any medium or format, as long as you give appropriate credit to the original author(s) and the source, provide a link to the Creative Commons licence and indicate if changes were made.

The images or other third party material in this chapter are included in the chapter's Creative Commons licence, unless indicated otherwise in a credit line to the material. If material is not included in the chapter's Creative Commons licence and your intended use is not permitted by statutory regulation or exceeds the permitted use, you will need to obtain permission directly from the copyright holder.

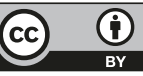

